\title{
Erratum to: Experimental Investigation of Seepage Properties of Fractured Rocks Under Different Confining Pressures
}

\author{
D. Ma X. X. Miao $\cdot$ Z. Q. Chen $\cdot$ X. B. Mao
}

Published online: 1 January 2015

(c) Springer-Verlag Wien 2014

Erratum to: Rock Mech Rock Eng (2013) 46:1135-1144

DOI 10.1007/s00603-012-0329-8

The spelling of Eqs. (9) and (10) was incorrect and some financial supports were omitted in the original publication of the article.

The corrected spelling of the Eqs. (9) and (10) should be

$k=\frac{\mu\left[\left(\sum_{i=1}^{n} v_{i}^{3}\right)^{2}-\sum_{i=1}^{n} v_{i}^{2} \sum_{i=1}^{n} v_{i}^{4}\right]}{\sum_{i=1}^{n} p_{i} v_{i}^{2} \sum_{i=1}^{n} v_{i}^{3}-\sum_{i=1}^{n} p_{i} v_{i} \sum_{i=1}^{n} v_{i}^{4}}$

$\beta=\frac{\sum_{i=1}^{n} p_{i} v_{i} \sum_{i=1}^{n} v_{i}^{3}-\sum_{i=1}^{n} p_{i} v_{i}^{2} \sum_{i=1}^{n} v_{i}^{2}}{\rho\left[\left(\sum_{i=1}^{n} v_{i}^{3}\right)^{2}-\sum_{i=1}^{n} v_{i}^{2} \sum_{i=1}^{n} v_{i}^{4}\right]}$

In the Acknowledgments, the last financial supports were omitted:

The National Basic Research Program of China (2013CB227900) and the National Natural Science Foundation of China (U1261201 and 51421003).

The online version of the original article can be found under doi:10.1007/s00603-012-0329-8.

D. Ma · X. X. Miao · Z. Q. Chen $(\varangle) \cdot$ X. B. Mao

State Key Laboratory for Geomechanics and Deep Underground

Engineering, School of Mechanics and Civil Engineering,

China University of Mining and Technology,

Xuzhou 221008, Jiangsu, China

e-mail: madancumt@gmail.com 